\title{
High prevalence of sexually transmitted infections and risk factors among HIV-positive individuals in Yunnan, China
}

\author{
Wei Tu' ${ }^{1}$, Yu-Ye Li² ${ }^{2}$, Yi-Qun Kuang ${ }^{3 *}$, Rong-Hui Xie ${ }^{4}$, Xing-Qi Dong ${ }^{4}$, Dan Zhang ${ }^{2}$, Yan-Ling Ma ${ }^{5}$,
} Wan-Yue Zhang ${ }^{5}$ and Lin Lu' ${ }^{1^{*}}$

\begin{abstract}
Background: Yunnan has the highest rates of HIV in China. Other treatable sexually transmitted infections (STIs) are associated with accelerated HIV transmission and poor ART outcomes, but are only diagnosed by syndromic algorithms.

Methods: We recruited 406 HIV-positive participants for a cross-sectional study (204 ART-naive and 202 receiving ART). Blood samples and first-voided urine samples were collected. Real-time polymerase chain reaction methods were used for diagnosing Chlamydia trachomatis (CT), Neisseria gonorrhea (NG) and Mycoplasma genitalium (MG). Syphilis and herpes simplex virus type 2 (HSV-2) tests were also performed.

Results: Among the 406 participants, the overall prevalence of STIs was $47.0 \%$ and $45.1 \%$ in ART-naive individuals and $49.0 \%$ in individuals receiving ART, respectively. The testing frequencies were $11.6 \%$ (11.8\% vs. 11.4\%), 33.2\% (29.4\% vs. $37.1 \%), 3.2 \%$ (3.4\% vs. $3.0 \%), 2.0 \%$ (3.4\% vs. $0.5 \%$ ) and $4.7 \%$ (6.4\% vs. $3.0 \%)$ for active syphilis, HSV-2, CT, NG and $M G$, respectively. The percentage of multiple infections in both groups was $10.8 \%$ (22/204) in ART-naive participants and 9.9\% (20/202) in participants receiving ART. Female sex, an age between 18 and 35 years, ever injecting drugs, homosexual or bisexual status, HIV/HBV coinfection, and not receiving ART were identified as risk factors. Selfreported asymptomatic patients were not eliminated from having a laboratory-diagnosed STI.

Conclusions: The STI prevalence was $47.0 \%$ (45.1\% vs. 49.0\%), and HSV-2, syphilis and MG were the most common STIs in HIV-infected individuals. We found a high prevalence (6.4\%) of MG in ART-naive individuals. HIV-positive individuals tend to neglect or hide their genital tract discomfort; thus, we suggest strengthening STI joint screening and treatment services among HIV-infected individuals regardless of whether they describe genital tract discomfort.
\end{abstract}

Keywords: HIV, Syphilis, CT, NG, MG, HSV-2, Risk factor

*Correspondence: yyeli2000@126.com; yq610433@hotmail.com; lulin@yncdc.cn

${ }^{1}$ Department of Public Health, Kunming Medical University,

Kunming 650500, China

${ }^{2}$ Department of Dermatology and Venereology, First Affiliated Hospital

of Kunming Medical University, Kunming 650032, China

${ }^{3}$ NHC Key Laboratory of Drug Addiction Medicine, First Affiliated

Hospital of Kunming Medical University, Kunming Medical University, Kunming 650032, China

Full list of author information is available at the end of the article

\section{Introduction}

Sexually transmitted infections (STIs) present an ongoing and persistent global public health challenge. The latest World Health Organization (WHO) report estimates that among people aged between 15 and 49 years, there are 374.3 million new curable STI cases every year of either Chlamydia trachomatis (CT), Neisseria gonorrhea (NG), Trichomonas vaginalis (TV), or syphilis [1]. This means that STIs are responsible for more than one million new original author(s) and the source, provide a link to the Creative Commons licence, and indicate if changes were made. The images or other third party material in this article are included in the article's Creative Commons licence, unless indicated otherwise in a credit line to the material. If material is not included in the article's Creative Commons licence and your intended use is not permitted by statutory regulation or exceeds the permitted use, you will need to obtain permission directly from the copyright holder. To view a copy of this licence, visit http://creativecommons.org/licenses/by/4.0/. The Creative Commons Public Domain Dedication waiver (http://creativeco mmons.org/publicdomain/zero/1.0/) applies to the data made available in this article, unless otherwise stated in a credit line to the data. 
infections per day [1]. Evidence shows that genital ulcers caused by STIs are an important clinical manifestation that can increase the risk of human immunodeficiency virus type 1 (HIV-1) acquisition and replication [2].

The synergistic effect between STIs and HIV can destroy the health of HIV-infected individuals in various ways. First, some STIs generally destroy mucosal barriers, induce genital inflammation and ulceration, increase viral shedding of HIV in the genital tract, and increase the scale of susceptible immune cells [e.g., $\mathrm{CD} 4^{+} \mathrm{T}$ cells and dendritic cells (DCs)] in the genital tract, which may facilitate HIV transmission to sex partners by increasing HIV target cells [3-5]. Second, STIs can also inhibit the immune responses of skin-resident DCs and create a microenvironment in the host that is conducive to HIV infection; STIs not only help themselves but also create a "yellow brick road" for HIV-1, which is transmitted mostly through the sexual route $[6,7]$. Third, STI-HIV coinfection can usually reduce the $\mathrm{CD}^{+} \mathrm{T}$ cell count and enhance the HIV viral load in blood plasma and genital secretions, which might decrease the effectiveness of antiretroviral therapy (ART) [8, 9]. Finally, STIHIV coinfection is significantly associated with persistent immune activation and poorer $\mathrm{CD} 4^{+} \mathrm{T}$ cell recovery [10]. HIV can also accelerate the progression of other STIs. When immune function is compromised, STI-HIV coinfection is more difficult to treat and may prolong the course of the disease [11].

Yunnan Province had the earliest epidemic of AIDS in China and was the most heavily affected area, and it has the largest number of HIV-positive individuals. Along with the rapid development of the economy, HIV prevalence has expanded from high-risk groups to the general population, and sexual transmission has now replaced unsafe intravenous drug use (IDU) as the dominant route of HIV transmission in China [12]. Epidemiological studies show that STIs are a public health problem in this area. Among miners in Yunnan Province, the prevalence of CT, NG, syphilis and herpes simplex virus type $2(\mathrm{HSV}-2)$ has been reported to be $4.8 \%, 0.8 \%, 1.8 \%$ and $9.6 \%$, respectively [13]. Among female sex workers involved in high-risk sexual behaviors, the prevalence of CT, NG, syphilis, HSV-2 and TV was $25.9 \%, 8.3 \%, 7.5 \%$, $68.1 \%$ and $10.6 \%$, respectively [14]. STIs such as CT, Mycoplasma genitalium (MG), syphilis and TV cause asymptomatic disease [15-18]. Hence, it is difficult to screen for and treat asymptomatic STIs, which can also induce genital inflammation and facilitate HIV transmission. Since HIV and STIs have almost the same routes of transmission and risk behaviors, we should develop a strategy to control the spread of these infections combined with HIV. However, limited studies have been conducted to determine the prevalence and risk factors for
STI-HIV coinfection among HIV-positive participants in Yunnan, China. This study aimed to evaluate the prevalence of STI coinfection (syphilis, HSV-2, CT, NG and MG) and the risk factors for coinfection among HIV-positive participants in Yunnan Province.

\section{Methods \\ Study design and population}

The study was conducted in Yunnan Provincial Hospital of Infectious Diseases, a public medical facility in Yunnan, China. It offers services such as voluntary counseling and testing for HIV, free ART, and psychotherapy for AIDS patients. Our target population was HIV-positive individuals who are looking for ART services in this institution. We used cluster sampling to recruit our participants in this cross-sectional study. According to the general recruitment process, trained interviewers conducted a face-to-face interview with each participant using a structured questionnaire. Measures included demographic characteristics, drug use, and sexual behaviors. Laboratory technicians collected approximately $5 \mathrm{ml}$ of venous blood using an anticoagulant tube, which was centrifuged immediately for 15 min to separate the serum. Finally, the participants provided a first-void urine specimen for the examination of CT, NG, and MG.

The cross-sectional study was conducted from September 2020 to June 2021 and included ART-naive participants and HIV-positive participants receiving ART who lived in Yunnan, China. A total of 406 HIV-positive participants (204 in the ART-naive group and 202 in the ART group) were recruited. Demographic data, including age, sex, nation, occupation, region, current marital status, education status, ever injecting drugs, sexual orientation, the number of sexual partners, condom use, HBV positivity, HCV positivity, routine blood tests, blood biochemistry, latest $\mathrm{CD} 4^{+} \mathrm{T}$ cell count and ART, were collected from the outpatient service system database and the questionnaire survey in Yunnan AIDS Care Center.

\section{Inclusion and exclusion criteria}

The inclusion criteria were as follows: (1) patients diagnosed with HIV/AIDS; (2) male or female patients, aged $\geq 18$ years; and (3) individuals who provided informed consent to participate in this study. The exclusion criteria were as follows: (1) patients known to be pregnant or lactating; (2) patients with serious liver, kidney, heart, brain and other dysfunctions or serious complications such as hypertension, diabetes, and coronary heart disease; (3) patients participating in other clinical studies; and (4) patients who used antimicrobials in the previous 15 days. 


\section{Data collection and STI detection}

Serum samples were tested for syphilis using Treponema pallidum particle agglutination (TPPA, Fujirebio Inc, Japan) and the toluidine red unheated serum test (TRUST, Shanghai Rongsheng Biotech Co. Ltd, China). Active syphilis-positive individuals were defined as those who were positive for both TPPA and TRUST. Serum samples were tested for HSV-2 immunoglobulin (IgG) antibodies using the HSV-2 IgG enzyme-linked immunoassay kit HerpesSelect 2 ELISA IgG (ACON Biotech Co. Ltd, China). First-void urine was collected from the participants for the detection of CT, NG and MG by polymerase chain reaction (PCR) using a CT RNA PCR kit, NG RNA PCR kit, and MG RNA PCR kit (Shanghai Rendu Biotech Co. Ltd, China). If any test appeared positive, the participants were notified and received treatment.

\section{Ethics approval and consent to participate}

This study was approved by the ethics review boards of Kunming Medical University. All study participants were anonymous, and written informed consent was obtained. All experiments were performed per the approved guidelines and regulations according to the principles expressed in the Declaration of Helsinki, and the experimental protocols were approved by the review board of Yunnan Provincial Hospital of Infectious Diseases (No. 202114).

\section{Statistical analyses}

The Chi-squared test or Fisher's exact test for categorical variables and the $t$ test for continuous variables were used to analyze differences in demographic characteristics and selected variables between the ART-naive group and ART group. Odds ratios (ORs) and their 95\% confidence intervals (CIs) were calculated by using logistic regression analyses to evaluate the association between STI-HIV coinfection and its related factors with age, sex, nation, occupation, region, current marital status, education status, sexual orientation, ever injecting drugs, the number of sexual partners, condom use, HBV positivity, $\mathrm{HCV}$ positivity, latest CD4 count and ART. All statistical analyses were performed using SPSS 19 software (IBM Company, New York, USA).

\section{Results}

\section{Characteristics of the participants}

A total of 406 HIV-infected participants agreed to participate in the study, among whom 204 (50.25\%) were ART-naive participants and 202 (49.75\%) were ART participants. The characteristics of the ART-naive participants and participants receiving ART are summarized in Table 1.
Compared to the participants receiving ART, the ARTnaive participants had a significantly higher unemployment rate $(16.2 \%$ versus $4 \%)$ and were more likely to be unmarried or single (68.1\% versus 51\%). A higher proportion of ever injecting drugs was found in the participants receiving ART (14.9\%) than in the ART-naive participants (5.9\%). Regarding sexual behaviors, compared to $2(1 \%)$ of the participants receiving ART, a total of 63 (30.9\%) ART-naive participants had multiple sexual partners in the past year. The mean number of sexual partners in the former group was $3.2( \pm 0.2)$ compared to $1( \pm 0.3)$ in the latter group. A higher proportion of never using condoms was found in the participants receiving ART (12.7\%) than in the ARTnaive participants $(0 \%)$. The prevalence of genital tract discomfort was only $0.5 \%(2 / 406)$, and most of the participants remained silent or self-reported as asymptomatic.

The average count of $\mathrm{CD} 4+\mathrm{T}$ cells in ART-naive participants was significantly lower than that in participants receiving ART (mean: 321 cells/ $\mu \mathrm{l}$ versus 807 cells/ $\mu \mathrm{l}$ ). Similarly, the average count of total T lymphocytes was lower in the ART-naive participants than in the participants receiving ART (mean: 1464 cells/ $\mu$ l versus 1890 cells $/ \mu \mathrm{l})$. Therefore, the CD4/CD8 count was also decreased in ART-naive participants (0.4 versus 0.9). Compared with the ART-naive participants, the participants receiving ART had a higher average white blood cell count, percentage of lymphocytes, lymphocyte count, platelet count and triglyceride count, but a lower average erythrocyte count and trioxypurine level (Fig. 1). In addition, the age, sex, nation, region, education, sexual orientation and other data between the ART-naive and ART groups were not significantly different $(p>0.05)$.

\section{Coinfections and multiple infections in ART-naive participants and participants receiving ART}

The prevalence of syphilis, HSV-2, CT, NG and MG among the participants was $19.9 \%$ (ART-naive: $19.6 \%$ and ART: $20.3 \%$ ), 33.2\% (ART-naive: $29.4 \%$ and ART: $37.1 \%$ ), 3.2\% (ART-naive: $3.4 \%$ and ART: $3.0 \%$ ), $2.0 \%$ (ART-naive: 3.4\% and ART: $0.5 \%$ ), and $4.7 \%$ (ART-naive: $6.4 \%$ and ART: $3.0 \%$ ), respectively (Table 2 ). The percentage of coinfections and multiple infections was $10.8 \%(22 / 204)$ in the ART-naive participants and 9.9\% (20/202) in the participants receiving ART.

For the ART-naive participants, the coinfection rate by decreasing order of prevalence was $54.5 \%(12 / 22)$ for Treponema pallidum (TP) with HSV-2, 9.1\% (2/22) for CT-HSV-2, 9.1\% (2/22) for TP-MG-HSV-2 and $4.5 \%$ (1/22) for MG-HSV-2, TP-NG, CT-NG, MG-NG, MG-TP, and CT-NG-MG-HSV-2. The participants in the ART group had a lower diversity of STIs. The coinfections by decreasing order of prevalence were $75.0 \%$ 
Table 1 Characteristics of ART-naive and ART HIV ${ }^{+}$participants

\begin{tabular}{|c|c|c|c|}
\hline Characteristics & $\begin{array}{l}\text { ART-naive }(n=204) \\
n(\%)\end{array}$ & $\begin{array}{l}\text { ART }(n=202) \\
n(\%)\end{array}$ & $p$ value \\
\hline \multicolumn{4}{|l|}{ General } \\
\hline Age, years, median (range) & $37(18-86)$ & $39.5(23-69)$ & \\
\hline $18-35$ & $93(45.6)$ & $74(36.6)$ & \\
\hline$\geq 36$ & $111(54.4)$ & $128(63.4)$ & 0.067 \\
\hline \multicolumn{4}{|l|}{ Sex } \\
\hline Male & $167(81.9)$ & $158(78.2)$ & \\
\hline Female & $37(18.1)$ & $44(21.8)$ & 0.358 \\
\hline \multicolumn{4}{|l|}{ Nation } \\
\hline Ethnic Han & $171(83.8)$ & $179(88.6)$ & \\
\hline Other & $33(162)$ & $23(11.4)$ & 0.162 \\
\hline \multicolumn{4}{|l|}{ Occupation } \\
\hline Employee & $121(59.3)$ & $115(56.9)$ & \\
\hline None & $33(16.2)$ & $8(4.0)$ & \\
\hline Unknown & $50(24.5)$ & $79(39.1)$ & 0.001 \\
\hline \multicolumn{4}{|l|}{ Region } \\
\hline Yunnan & $192(94.1)$ & $194(96.0)$ & \\
\hline Other province & $12(5.9)$ & $8(4.0)$ & 0.371 \\
\hline \multicolumn{4}{|l|}{ Current marital status } \\
\hline Married & $65(31.9)$ & $99(49.0)$ & \\
\hline Unmarried or single & $139(68.1)$ & $103(51.0)$ & $<0.001$ \\
\hline \multicolumn{4}{|l|}{ Education } \\
\hline Up to primary & $120(58.8)$ & $114(56.4)$ & \\
\hline Above primary & $84(41.2)$ & $88(43.6)$ & 0.626 \\
\hline \multicolumn{4}{|l|}{ Sexual orientation } \\
\hline Heterosexual & $125(61.3)$ & $135(66.8)$ & \\
\hline Homosexual/bisexual & $79(38.7)$ & $67(33.2)$ & 0.243 \\
\hline \multicolumn{4}{|l|}{ Ever injected drugs } \\
\hline Yes & $12(5.9)$ & $30(14.9)$ & \\
\hline No & $192(94.1)$ & $172(85.1)$ & 0.003 \\
\hline \multicolumn{4}{|l|}{ No. of sexual partners } \\
\hline Single & $58(28.4)$ & $53(26.2)$ & \\
\hline Multiple & $63(30.9)$ & $2(1.0)$ & \\
\hline Unknown & $83(40.7)$ & $147(72.8)$ & $<0.001$ \\
\hline \multicolumn{4}{|l|}{ Condom use } \\
\hline Consistent/casual & $121(59.3)$ & $79(39.1)$ & \\
\hline Never & $26(12.7)$ & $0(0.0)$ & \\
\hline Unknown & $57(28.0)$ & $123(60.9)$ & $<0.001$ \\
\hline \multicolumn{4}{|l|}{ Genital tract discomfort } \\
\hline Yes & $2(1.0)$ & $0(0)$ & \\
\hline No or unanswered & $202(99.0)$ & $202(100.0)$ & 0.483 \\
\hline CD4, median (range) & $273(1-1148)$ & $731(551-2200)$ & \\
\hline Normal & $28(13.7)$ & $202(100.0)$ & \\
\hline Down & $176(86.3)$ & $0(0.0)$ & $<0.001$ \\
\hline $\mathrm{CD} 4 / \mathrm{CD} 8$, median (range) & $0.25(0.02-3.19)$ & $0.88(0.30-6.75)$ & \\
\hline Normal & $16(7.8)$ & $135(66.8)$ & \\
\hline Down & $160(78.4)$ & $65(32.2)$ & $<0.001$ \\
\hline Total T lymphocytes, median (range) & $1314(112-5416)$ & $1815(923-3840)$ & \\
\hline Normal & $111(54.4)$ & $180(89.1)$ & \\
\hline Down & $39(19.1)$ & $1(0.5)$ & $<0.001$ \\
\hline
\end{tabular}

$P$ values were based on the Chi-square test (or Fisher exact test) for categorical variables

The statistical significance was indicated as ${ }^{*} p<0.05$, and ${ }^{* *} p<0.001$

Created by the authors 

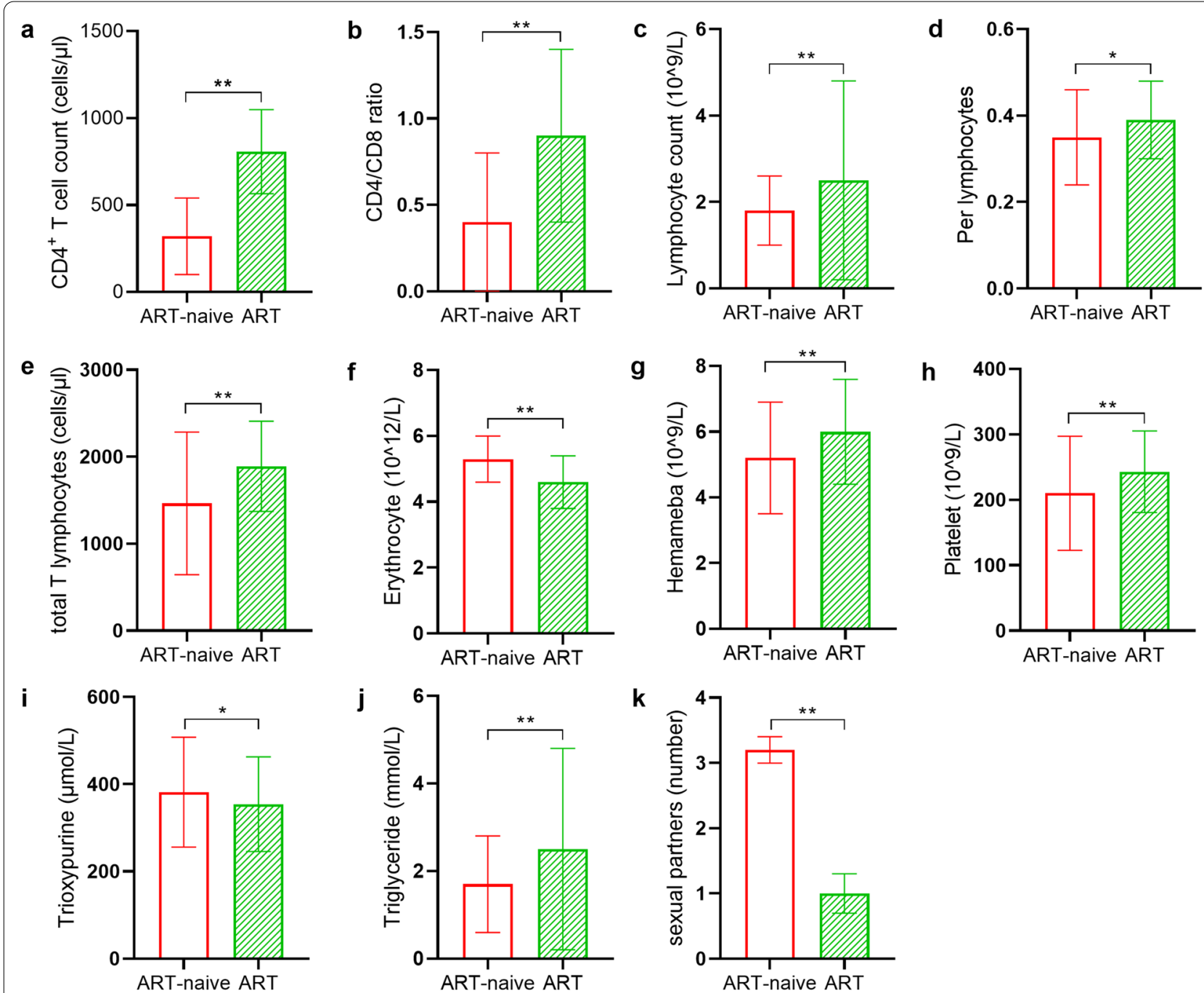

Fig. 1 Comparison of laboratory data between the ART-naive participants and participants receiving ART. a CD4 ${ }^{+} \mathrm{T}$ cell count (cells/ $\left.\mu \mathrm{ll}\right)$. b Ratio of $\mathrm{CD}^{+} \mathrm{T}$ cell count $/ \mathrm{CD} 8^{+} \mathrm{T}$ cell count. $\mathbf{c}$ Lymphocyte count $\left(10^{9} / \mathrm{L}\right)$. $\mathbf{d}$ The percentage of lymphocytes (\%). e Total T lymphocyte count (cells/ $\left.\mu \mathrm{l}\right) . \mathbf{f}$ Erythrocyte count $\left(10^{12} / \mathrm{L}\right)$. $\mathbf{g}$ Hemameba count $\left(10^{9} / \mathrm{L}\right)$. h Platelet count $\left(10^{9} / \mathrm{L}\right)$. i Trioxypurine level $(\mu \mathrm{mol} / \mathrm{L})$. $\mathbf{j}$ Triglyceride level (mmol/L). $\mathbf{k}$ Number of sexual partners. The red bar shows the ART-naive group $(n=204)$, and the green bar shows the ART group $(n=202)$. Data are presented as the mean \pm SEM. Statistical significance was indicated as * $p<0.05$ and ${ }^{* *} p<0.001$. "Created by the authors"

(15/20) for TP-HSV-2, $10.0 \%(2 / 20)$ for MG-HSV-2, and $5 \%(1 / 20)$ for TP-NG, TP-NG-MG and TP-MGHSV-2 (Fig. 2).

\section{Factors associated with STI-HIV coinfection}

All of the items between the STI-HIV coinfection groups were included in the logistic regression model (Table 3). For all participants, the logistic regression analyses revealed that female sex was significantly associated with STI-HIV coinfection risk $(\mathrm{OR}=3.46,95 \%$ CI $1.95-6.15, p<0.001)$. In the further stratification analysis of the ART-naive and ART groups, female sex also showed consistent significant associations with STI-HIV coinfection risk $(\mathrm{OR}=3.89$, 95\% CI 1.599.50, $p=0.003$ versus $\mathrm{OR}=4.21,95 \%$ CI $1.84-9.61$, $p=0.001)$.

The identification of risk factors for each STI was determined by a logistic regression model. In the logistic regression analysis, all variables were adjusted, and the following variables remained in the model as risk factors: an age $>36$ years $(\mathrm{OR}=0.33,95 \%$ CI $0.13-0.87$, $p=0.024$ ) reduced the risk of TP-HIV coinfection. An 
Table 2 Prevalence of sexually transmitted infections among $\mathrm{HIV}^{+}$participants

\begin{tabular}{lccc}
\hline Variable & $\begin{array}{l}\text { Total }(\boldsymbol{n}=\mathbf{4 0 6}) \\
\text { Case number (\%) }\end{array}$ & $\begin{array}{l}\text { ART-naïve }(\boldsymbol{n}=\mathbf{2 0 4}) \\
\text { Case number (\%) }\end{array}$ & $\begin{array}{l}\text { ART }(\boldsymbol{n}=\mathbf{2 0 2}) \\
\text { Case number (\%) }\end{array}$ \\
\hline $\begin{array}{l}\text { Syphilis } \\
\text { TPPA + }\end{array}$ & $81(19.9)$ & $40(19.6)$ & $41(20.3)$ \\
TPPA+TRUST+ & $47(11.6)$ & $24(11.8)$ & $23(11.4)$ \\
HSV-2 lgG+ & $135(33.2)$ & $60(29.4)$ & $75(37.1)$ \\
Neisseria gonorrhoeae & $8(2.0)$ & $7(3.4)$ & $1(0.5)$ \\
Chlamydia trachomatis & $13(3.2)$ & $7(3.4)$ & $6(3.0)$ \\
Mycoplasma genitalium & $19(4.7)$ & $13(6.4)$ & $6(3.0)$ \\
STI & $191(47.0)$ & $92(45.1)$ & $99(49.0)$ \\
\hline
\end{tabular}

Created by the authors

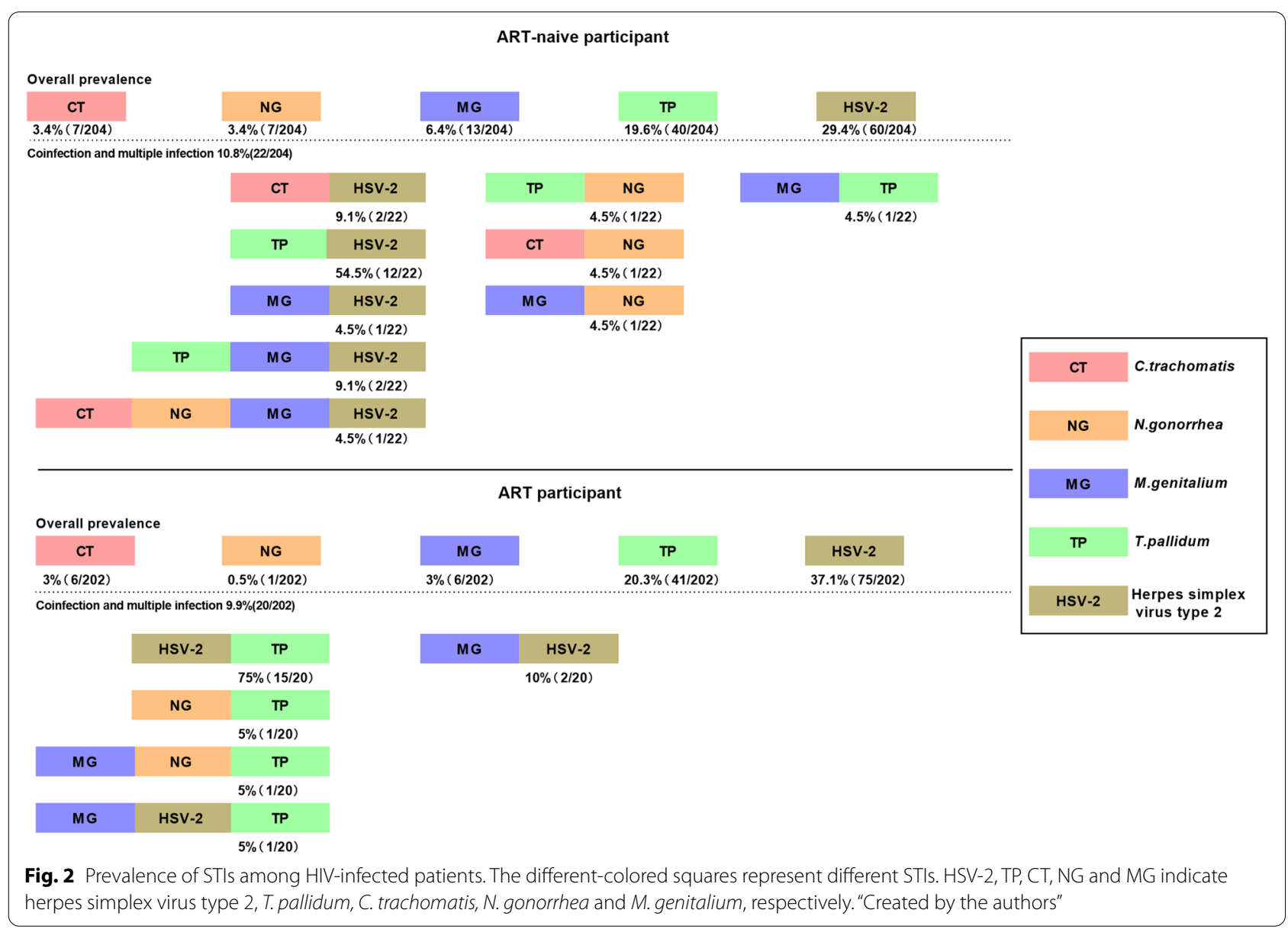

age $>36$ years $(\mathrm{OR}=2.24,95 \%$ CI $1.20-4.20, P=0.012)$ and female sex $(\mathrm{OR}=3.47,95 \%$ CI 1.95-6.16, $p<0.001)$ significantly increased the risk of an HIVHSV-2 coinfection. Ever injecting drugs (OR $=171.00$, 95\% CI 13.80-2133.40, $P<0.001)$ and female sex $(\mathrm{OR}=9.60,95 \%$ CI 1.46-63.06, $P=0.019)$ strongly associated with $\mathrm{CT}-\mathrm{HIV}$ coinfection risk. Coinfection with $\mathrm{HBV}(\mathrm{OR}=100.50$, 95\% CI 4.70-2168.70, $p=0.003)$ increased the risk of NG-HIV coinfection; however, receiving antiretroviral therapy $(\mathrm{OR}=0.03$, 95\% CI $0.001-0.75, p=0.032$ ) became a protective factor against NG-HIV coinfection. We also found 
Table 3 Logistic regression analyses of related factors associated with curable STI-HIV coinfection among HIV+ participants

\begin{tabular}{|c|c|c|c|c|c|c|c|c|c|}
\hline \multirow[t]{2}{*}{ Variable } & \multicolumn{3}{|c|}{$\begin{array}{l}\text { STI-HIV coinfection rate, }(N=406) \text {, } \\
n(\%)\end{array}$} & \multicolumn{3}{|c|}{$\begin{array}{l}\text { STI-HIV coinfection rate on ART-naive, } \\
(N=204), n(\%)\end{array}$} & \multicolumn{3}{|c|}{$\begin{array}{l}\text { STI-HIV coinfection rate on } \\
\text { ART, }(N=202), n(\%)\end{array}$} \\
\hline & n/N (\%) & OR $(95 \% \mathrm{Cl})$ & Pvalue & n/N (\%) & OR $(95 \% \mathrm{Cl})$ & Pvalue & n/N (\%) & OR $(95 \% \mathrm{Cl})$ & Pvalue \\
\hline \multicolumn{10}{|l|}{ Age, years } \\
\hline 18-35 & $72 / 167(43.1)$ & Ref. & & 37/93 (39.8) & Ref. & & $35 / 74(47.3)$ & Ref. & \\
\hline$\geq 36$ & 119/239(49.8) & $1.24(0.70-2.19)$ & 0.461 & $55 / 111(49.5)$ & $1.12(0.48-2.60)$ & 0.791 & $64 / 128(50.0)$ & $1.08(0.45-2.62)$ & 0.858 \\
\hline \multicolumn{10}{|l|}{ Sex } \\
\hline Male & $136 / 325(41.8)$ & Ref. & & $66 / 167(39.5)$ & Ref. & & $70 / 158(44.3)$ & Ref. & \\
\hline Female & $55 / 81(67.9)$ & $3.46(1.95-6.15)$ & $<0.001$ & 26/37 (70.3) & $3.89(1.59-9.50)$ & 0.003 & 29/44 (65.9) & $4.21(1.84-9.61)$ & 0.001 \\
\hline \multicolumn{10}{|l|}{ Nation } \\
\hline Ethnic Han & $168 / 350(48.0)$ & Ref. & & 79/171 (46.2) & Ref. & & $89 / 179(49.7)$ & Ref. & \\
\hline Other & 23/56 (41.1) & $0.66(0.36-1.22)$ & 0.186 & 13/33 (39.4) & $0.60(0.25-1.42)$ & 0.245 & 10/23 (43.5) & $0.61(0.23-1.62)$ & 0.324 \\
\hline \multicolumn{10}{|l|}{ Occupation } \\
\hline Employee & 110/236 (46.6) & Ref. & & $52 / 121(42.9)$ & Ref. & & $58 / 115(50.4)$ & Ref. & \\
\hline None & $21 / 41(51.2)$ & $1.26(0.61-2.59)$ & 0.528 & $16 / 33(48.5)$ & $1.06(0.44-2.54)$ & 0.896 & $5 / 8(62.5)$ & $2.70(0.56-13.05)$ & 0.216 \\
\hline Others & $60 / 129(46.5)$ & $0.89(0.55-1.42)$ & 0.614 & 24/50 (48.0) & $0.94(0.44-2.01)$ & 0.880 & $36 / 79(45.6)$ & $1.01(0.52-1.99)$ & 0.966 \\
\hline \multicolumn{10}{|l|}{ Region } \\
\hline Other province & $10 / 20(50.0)$ & Ref. & & $5 / 12(41.7)$ & Ref. & & $5 / 8(62.5)$ & Ref. & \\
\hline Yunnan & 181/386 (46.9) & $1.08(0.43-2.73)$ & 0.864 & 87/192 (45.3) & $1.13(0.31-4.21)$ & 0.853 & $94 / 194(48.4)$ & $0.92(0.21-4.09)$ & 0.916 \\
\hline \multicolumn{10}{|l|}{ Current marital status } \\
\hline Married & 75/164 (45.7) & Ref. & & $30 / 65(46.2)$ & Ref. & & 45/99 (45.4) & Ref. & \\
\hline Unmarried/single & 116/242 (47.9) & $1.31(0.79-2.18)$ & 0.304 & 62/139(44.6) & $1.06(0.49-2.26)$ & 0.884 & $54 / 103(52.4)$ & $1.52(0.71-3.25)$ & 0.278 \\
\hline \multicolumn{10}{|l|}{ Education } \\
\hline Up to primary & $113 / 234(48.3)$ & Ref. & & $58 / 120(48.3)$ & Ref. & & $55 / 114(48.2)$ & Ref. & \\
\hline Above primary & 78/172 (45.3) & $1.13(0.69-1.87)$ & 0.622 & $34 / 84(40.5)$ & $1.03(0.49-2.18)$ & 0.932 & $44 / 88(50.0)$ & $1.32(0.64-2.73)$ & 0.461 \\
\hline \multicolumn{10}{|l|}{ Sexual orientation } \\
\hline Heterosexual & $125 / 260(48.1)$ & Ref. & & $61 / 125(48.8)$ & Ref. & & $64 / 135$ (47.4) & Ref. & \\
\hline $\begin{array}{l}\text { Homosexual/ } \\
\text { bisexual }\end{array}$ & $66 / 146(45.2)$ & $1.55(0.88-2.72)$ & 0.129 & $31 / 79(39.2)$ & $1.39(0.62-3.15)$ & 0.426 & $35 / 67(52.2)$ & $1.58(0.67-3.76)$ & 0.297 \\
\hline \multicolumn{10}{|l|}{ Ever injected drugs } \\
\hline No & $168 / 364(46.1)$ & Ref. & & $85 / 192(44.3)$ & Ref. & & $83 / 172(48.3)$ & Ref. & \\
\hline Yes & $23 / 42(54.8)$ & $1.40(0.64-3.08)$ & 0.396 & $7 / 12(58.3)$ & $1.19(0.22-6.59)$ & 0.839 & 16/30 (53.3) & $1.71(0.67-4.38)$ & 0.265 \\
\hline \multicolumn{10}{|c|}{ No. of sexual partners } \\
\hline Single & $53 / 111(47.7)$ & Ref. & & $29 / 58(50.0)$ & Ref. & & $24 / 53(45.3)$ & Ref. & \\
\hline Multiple & $21 / 65(32.3)$ & $0.48(0.23-1.00)$ & 0.051 & 19/63 (30.2) & $0.42(0.18-0.98)$ & 0.054 & $2 / 2(100)$ & & \\
\hline Others & $117 / 230(50.9)$ & $1.28(0.66-2.46)$ & 0.466 & $44 / 83(53.0)$ & $1.32(0.51-3.41)$ & 0.567 & 73/147 (49.7) & $1.33(0.48-3.72)$ & 0.588 \\
\hline \multicolumn{10}{|l|}{ Condom use } \\
\hline Consistent & $55 / 118(46.6)$ & Ref. & & $18 / 39(46.2)$ & Ref. & & $37 / 79(46.8)$ & Ref. & \\
\hline Casual/never & $47 / 108(43.5)$ & $1.27(0.63-2.58)$ & 0.508 & 47/108 (43.5) & $0.90(0.37-2.17)$ & 0.815 & 0 & & \\
\hline Others & $89 / 180(49.4)$ & $0.85(0.45-1.60)$ & 0.607 & $27 / 57(47.4)$ & $0.49(0.16-1.44)$ & 0.193 & $62 / 123(50.4)$ & $1.31(0.54-3.17)$ & 0.545 \\
\hline \multicolumn{10}{|l|}{ CD4 count } \\
\hline$\geq 550$ & $112 / 230(48.7)$ & Ref. & & $13 / 28(46.4)$ & Ref. & & 99/202 (49.0) & Ref. & \\
\hline$<550$ & 79/176 (44.9) & $0.90(0.52-1.56)$ & 0.714 & 79/176 (44.9) & $0.93(0.37-2.33)$ & 0.872 & $0(0.0)$ & NA & NA \\
\hline \multicolumn{10}{|l|}{ HBV } \\
\hline Negative & $174 / 374(46.5)$ & Ref. & & 77/182 (42.3) & Ref. & & $97 / 192(50.5)$ & Ref. & \\
\hline Positive & $17 / 32(53.1)$ & $1.19(0.55-2.57)$ & 0.654 & 15/22 (68.2) & $2.76(1.00-7.67)$ & 0.051 & $2 / 10(20.0)$ & $0.25(0.05-1.18)$ & 0.080 \\
\hline \multicolumn{10}{|l|}{$\mathrm{HCV}$} \\
\hline Negative & $177 / 381(46.5)$ & Ref. & & $82 / 188(43.6)$ & Ref. & & 95/193 (49.2) & Ref. & \\
\hline Positive & 14/25 (56.0) & $1.04(0.40-2.74)$ & 0.934 & 10/16 (62.5) & $1.50(0.33-6.80)$ & 0.598 & $4 / 9(44.4)$ & $0.58(0.12-2.89)$ & 0.501 \\
\hline
\end{tabular}




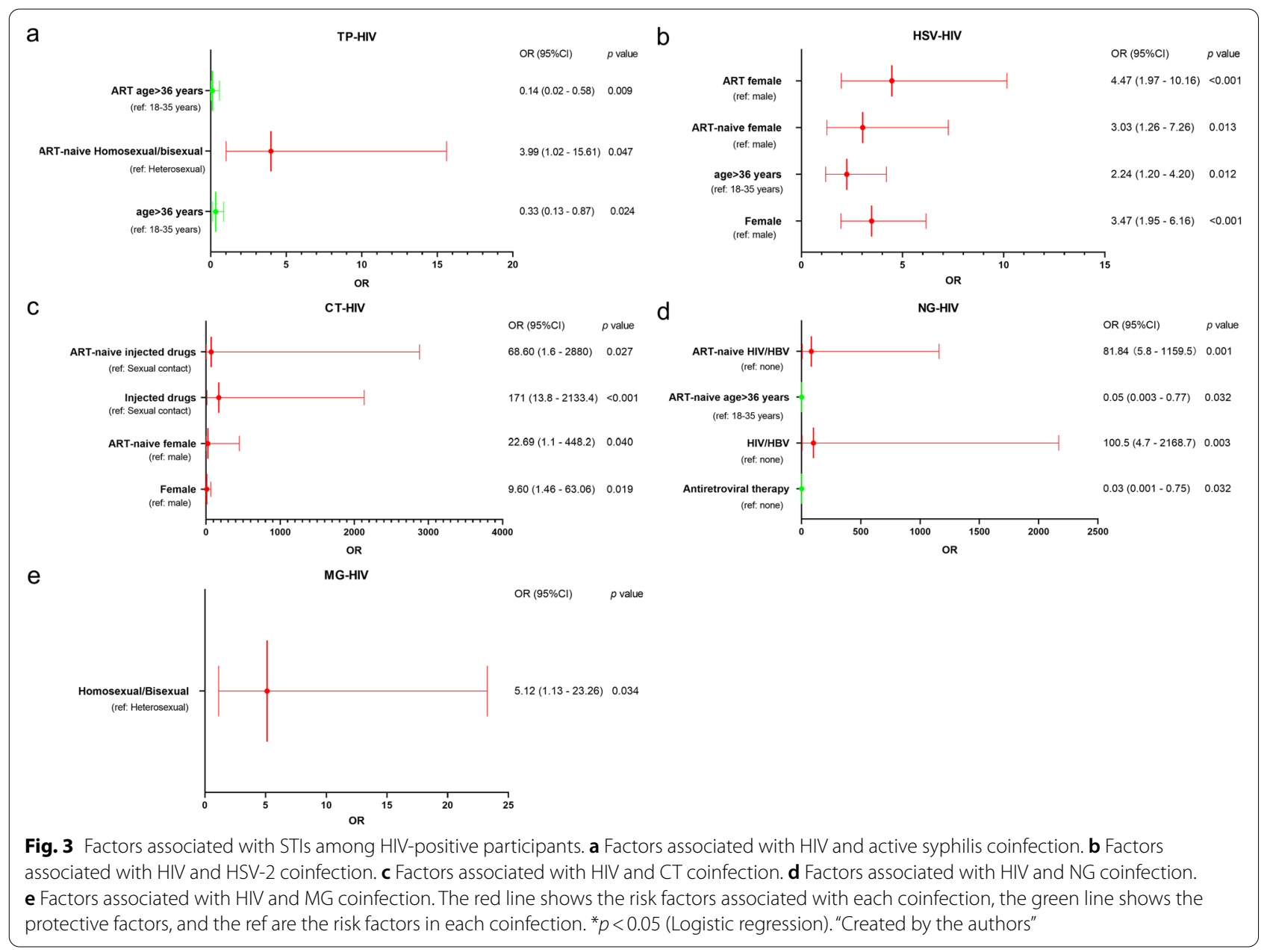

that homosexual or bisexual status (OR $=5.12,95 \%$ CI 1.13-23.26, $p=0.034$ ) was significantly associated with an increase in MG-HIV coinfection. The logistic regression analysis showed the following variables as risk factors for each STI coinfection among participants with ART-naive status: homosexual or bisexual status $(\mathrm{OR}=3.99,95 \%$ CI $1.02-15.61, p=0.047)$ for TP-HIV coinfection, female sex $(\mathrm{OR}=3.03$, 95\% CI 1.26-7.26, $p=0.013$ ) for HIV-HSV-2 coinfection, ever injecting drugs $(\mathrm{OR}=68.60,95 \% \mathrm{CI}$ $1.60-2880.00, p=0.027)$ and female sex $(\mathrm{OR}=22.69$, 95\% CI $1.10-448.20, p=0.040)$ for CT-HIV coinfection, an age $>36$ years $(\mathrm{OR}=0.05,95 \%$ CI $0.003-0.77$, $p=0.032)$ and coinfection with HBV (OR $=81.84,95 \%$ CI 5.80-1159.50, $p=0.001$ ) for NG-HIV (Fig. 3).

\section{Discussion}

This is the first study of STI prevalence that included a large number of new HIV-infected people and was detected by blood samples and first-voided urine samples in Yunnan, China. In the present study, a rather high STI prevalence among HIV-positive individuals was confirmed, namely, $47.0 \%(191 / 406)$ in total, $45.1 \%(91 / 204)$ in ART-naive individuals and 49.0\% (99/202) in individuals receiving ART. This prevalence is much higher than the observed prevalence of $5.3 \%$ in HIV-positive individuals in Nepal [19], 11.1\% in women living with HIV/ AIDS (WLHA) in Uganda [20] and 23.5\% in HIV-infected men who have sex with men (MSM) in China [21], but the prevalence was less than that of $60.6 \%$ in female sex workers in Peru [22] and 60.5\% in HIV-infected women in Zimbabwe [23]. The prevalence of genital tract discomfort was $0.5 \%(2 / 406)$, which was lower than the STI prevalence. It was interesting to find that HIV-positive individuals tend to neglect or hide their genital tract discomfort. However, our health policy is that no symptoms means no screening, and these reasons may contribute to the high prevalence of STIs. In this study, we found that the overall prevalence of STIs among individuals receiving ART was slightly higher than that among ART-naive 
individuals, although the difference was not statistically significant. This may be associated with the high prevalence of HSV-2/HIV coinfection: 29.4\% (60/204) in the ART-naive group versus $37.1 \%$ (75/202) in the ART group. In HIV-positive individuals, genital herpes tends to recurrently attack, and some individuals are even asymptomatic [24]. Without intervention, HSV-2 infection will persist, accumulate, and be transmitted to people living with HIV/AIDS. However, the ART-naive group had a higher diversity of STIs, coinfections and more sexual partners, and the prevalence of CT, NG and MG was also higher in this study. We believe that ARTnaive individuals may face greater threats of STIs and remain in a more dangerous situation.

HSV-2 was the most common STI that was detected, with an overall prevalence of $33.2 \%(135 / 406)$ in HIVpositive individuals in this study. The prevalence of HSV-2/HIV coinfection was much higher than the $6 \%-13 \%$ observed in noninjecting drug users [25], but it was less than that of $48.6 \%$ in HIV-positive MSM in Shenyang [26]. Active syphilis was also a familiar STI that was observed, with a prevalence of $11.8 \%(24 / 204)$ in the ART-naive group and $11.4 \%(23 / 202)$ in the ART group. The result is similar to the prevalence of $11.3 \%$ that was detected in HIV-positive MSM in Zhejiang Province [27]; however, the prevalence of active syphilis detected in our study was less than that of $34.3 \%$ in HIV-positive MSM in Shenyang and $82.9 \%$ in HIV-positive MSM in the United States [26, 28]. HSV-2 and TP can induce genital ulceration, which plays an important role in facilitating the acquisition and transmission of HIV and other STIs. Evidence shows that $60.7 \%$ of HSV-2 infections and $3.9 \%$ of TP infections could be detected in ulcer specimens, and $68 \%$ of HSV-positive participants were coinfected with HIV in South Africa [29]. Moreover, among people with genital ulcers, the positivity rates of HSV, TP and HIV were $38.5 \%, 16.0 \%$ and $52.2 \%$, respectively, in Zimbabwe [30].

The prevalence of $\mathrm{CT}$ that was detected in the two groups of participants $(3.4 \%$ vs. $3.0 \%)$ was larger than that of $0.9 \%$ that was identified in WLHA [20], while it was smaller than that of $11.1 \%$ in MSM in Port-au-Prince [31]. The prevalence of NG identified in our study $(3.4 \%$ vs. $0.5 \%$ ) was lower than that of $5.4 \%$ that was observed in WLHA [20] and that of 7.2\% in HIV-positive MSM in Birmingham [32].

Very few studies of MG prevalence have been assessed and generally associated with specific groups of women [33]. Our study provides the first report of MG prevalence among ART-naive individuals in Yunnan. We identified a prevalence of $6.4 \%(13 / 204)$ of MG infection in the ART-naive participants. This prevalence was higher than that of $2.4 \%$ that was detected in HIV-infected women in Brazil [34], but the prevalence was lower than that of $10.5 \%$ in HIV-positive women in Zimbabwe [35]. However, increasing evidence shows an association between MG and HIV infections. The report shows that the prevalence of MG was comparable to that for CT, NG and HSV among HIV-positive men, and MG infection may be associated with HIV shedding in the genital tract [35]. MG infection had a prevalence of $21.4 \%$ among HIV-infected pregnant women and was associated with higher plasma HIV levels [36]. This finding was notable: the prevalence of MG infection in the ART-naive participants was $6.4 \%$, which was higher than that of CT or NG infection in the two groups. Therefore, we need further research to understand MG infection in the HIV-positive population in Yunnan Province.

We found that ART-naive individuals had a higher unemployment rate, unmarried rate, more sexual partners per year and less use of condoms than individuals receiving ART. Unemployment and a low income make marrying impractical in China, and individuals are more likely to proceed with unprotected sexual behavior for economic gains. However, individuals receiving ART recognized their condition and had more convenient access to STI preventative information. Our results show that the proportion of ever injecting drugs in the ART-naive group was lower than that in the ART group because sexual transmission has become the dominant route of HIV transmission. With the government's strict control of drugs, intravenous drug use is rare. The average $\mathrm{CD}^{+} \mathrm{T}$ cell count, total $\mathrm{T}$ lymphocyte, count $\mathrm{CD} 4 / \mathrm{CD} 8$ count, lymphocyte count and percentage of lymphocytes in the ART-naive participants were significantly lower than those in the participants receiving ART. In China, in 2015, the enrollment criteria for ART changed such that individuals should receive ART once they are diagnosed as HIV-positive. ART can inhibit the replication of $\mathrm{HIV}-1$ and promote the gradual recovery of $\mathrm{CD} 4^{+} \mathrm{T}$ cell counts [37]. We found a significant promotion of CD4 ${ }^{+}$ $\mathrm{T}$ cells and lymphocytes in the ART group. The participants receiving ART had higher average counts of white blood cells, platelets and triglycerides but a lower average erythrocyte count and trioxypurine level. Lipid abnormalities and metabolic complications associated with ART may explain this finding $[38,39]$.

Our findings revealed that females were more likely to have curable STIs (CT, NG, MG, HSV-2 or active syphilis), regardless of being in the ART-naive group or ART group. Two variables, female sex and ever injecting drugs, showed a significant association with CT-HIV coinfection. Similarly, female sex and an age $>36$ years showed an association with HSV-2/HIV coinfection. 
Homosexual or bisexual status was associated with a significantly increased MG-HIV coinfection risk. However, an age between 18 and 35 years was a risk factor for TP-HIV or NG-HIV coinfection. Other risk factors for TP-HIV coinfection were homosexual or bisexual status, and NG-HIV coinfection or HIV/HBV coinfection. Participants receiving ART were less likely to have NGHIV coinfection than those not receiving ART. In conclusion, the risk factors associated with sexually transmitted infections among HIV-positive individuals were female sex, an age between 18 and 35 years, ever injecting drugs, homosexual or bisexual status, HIV/HBV coinfection, and not receiving ART. A study revealed that multiple STIs were mainly found among MSM (14.8\%) and bisexual individuals (23.5\%), and MSM had the highest sex behavior-related risk for STIs in southern Italy [40].

Our results on STI-HIV coinfection have important implications for improving STI screening and treatment services among HIV-positive individuals. Evidence shows that many people with STIs are asymptomatic. The prevalence of syphilis was $13.5 \%$; among the cases, 91.3\% were asymptomatic cases among women in China. Most of the people with anorectal (93.3\%) and urethral (79.2\%) MG infections were asymptomatic among MSM in western Sydney [15]. A Nigerian study showed that over $95 \%$ of STI cases were asymptomatic among MSM [41]. In Yunnan, we found that some hospitals and clinics may not screen for other STIs when diagnosing a new HIV-positive patient, especially in resource-poor settings and rural areas, unless they have obvious symptoms. The symptom-based management of STIs is limited, and current and future trends are the laboratory diagnosis of STIs. Point-of-care testing and microfluidic and highthroughput omics technologies promise to revolutionize the diagnosis of STIs [42]. Therefore, strategies to screen all HIV-positive individuals for HSV-2, syphilis, MG, and so on would be necessary. Untreated STIs may facilitate HIV acquisition and transmission and reduce the effectiveness of antiviral therapy.

There are several limitations to the research. This was a cross-sectional study, and the participants were not random. Our collected information might have been compromised by recall bias and social desirability bias, as sexual behavior is private information to participants. Our recruitment was limited to one infectious hospital, and the regional diversity of the samples was not enough, which might influence the external validity of our results.

\section{Conclusions}

In conclusion, we identified a high prevalence of STIs among ART-naive and HIV-positive individuals receiving ART in Yunnan. HSV-2, syphilis and MG were the most common STIs in HIV-positive individuals. HIV-positive individuals tend to neglect or hide their genital tract discomfort; thus, we suggest strengthening STI joint screening and treatment services among HIV-infected individuals regardless of whether they describe genital tract discomfort. The prevalence of MG was high in ART-naive participants, and further research is needed to understand this association. Younger patients, women, those who ever injected drugs, homosexual or bisexual individuals, those with coinfection with $\mathrm{HBV}$ and those not receiving ART should be a focus for interventions to decrease STIs.

\section{Acknowledgements \\ The authors would like to thank all the participants in this study, the staff of the Biomedical Laboratory of Dermatology in the First Affiliated Hospital of Kunming Medical University and the Yunnan Provincial Infectious Disease Hospital for their assistance in this study.}

\section{Authors' contributions}

$\mathrm{LL}, \mathrm{YYL}$ and $\mathrm{YQK}$ conceived and designed the study. WT, RHX, XQD and DZ contributed to the conduction of the experiment and data acquisition. WT, YLM, WYZ and YQK analyzed and interpreted the data. WT and YQK drafted the manuscript. $L L, Y Y L$ and $Y Q K$ contributed to the critical revision of the manuscript for important intellectual content. YYL and LL obtained funding. All authors read and approved the final manuscript.

\section{Funding}

The work was supported by the Project of AIDS Bureau of Yunnan Province, grants from the National Natural Science Foundation of China (81860553 and 32060177), "Ten-thousand Talents Program" of Yunnan Province (YNWRMY-2018-039), Medical Leadership Foundation of Health and Family Planning Commission of Yunnan Province, China (L-201613), Yunnan Province Clinical Research Center for Skin Immune Diseases (2019ZF012), and Yunnan Province Clinical Center for Skin Immune Diseases (ZX2019-03-02).

\section{Availability of data and materials}

The majority of the datasets used and/or analyzed during the current study are available from the indicated published resources. The remaining data, including the model code, are available from the corresponding author on reasonable request.

\section{Declarations}

Ethics approval and consent to participate

This study was approved by the review board of Yunnan Provincial Hospital of Infectious Diseases, and written informed consent was obtained from the study participants. All experiments were performed in accordance with the approved guidelines and regulations according to the principles expressed in the Declaration of Helsinki, and the experimental protocols were approved by the institutional review board.

\section{Consent for publication}

Not applicable.

\section{Competing interests}

The authors declare no conflicts of interest.

\section{Author details}

${ }^{1}$ Department of Public Health, Kunming Medical University, Kunming 650500, China. ${ }^{2}$ Department of Dermatology and Venereology, First Affiliated Hospital of Kunming Medical University, Kunming 650032, China. ${ }^{3} \mathrm{NHC}$ Key Laboratory of Drug Addiction Medicine, First Affiliated Hospital of Kunming Medical University, Kunming Medical University, Kunming 650032, China. ${ }^{4}$ Yunnan Provincial Hospital of Infectious Diseases/Yunnan AIDS Care Center (YNACC), Anning 650300, China. ${ }^{5}$ Yunnan Centers for Disease Control and Prevention, Kunming 650022, China. 
Received: 27 September 2021 Accepted: 4 January 2022

Published online: 13 January 2022

\section{References}

1. Global progress report on HIV, viral hepatitis and sexually transmitted infections. 2021. https://www.who.int/publications/i/item/9789240027 077. Accessed 10 Jan 2022.

2. Torrone EA, Morrison CS, Chen PL, Kwok C, Francis SC, Hayes RJ, et al. Prevalence of sexually transmitted infections and bacterial vaginosis among women in sub-Saharan Africa: an individual participant data meta-analysis of 18 HIV prevention studies. PLoS Med. 2018;15(2): e1002511.

3. Kalichman SC, Pellowski J, Turner C. Prevalence of sexually transmitted co-infections in people living with HIV/AIDS: systematic review with implications for using HIV treatments for prevention. Sex Transm Infect. 2011;87(3):183-90.

4. Storim J, Verheyen J, Wolff E, Wohlschlaeger J, Von Heintschel Heinegg E, Schadendorf D, et al. Antiretroviral therapy suppresses rectal HIV-RNA shedding despite inflammation in MSM with rectal C. trachomatis and N. gonorrhoeae infections-a cross-sectional, single-center study. Sex Transm Infect. 2019;95(2):95-8.

5. Ward H, Ronn M. Contribution of sexually transmitted infections to the sexual transmission of HIV. Curr Opin HIV AIDS. 2010;5(4):305-10.

6. Crisci E, Svanberg C, Ellegard R, Khalid M, Hellblom J, Okuyama K, et al. HSV-2 cellular programming enables productive HIV infection in dendritic cells. Front Immunol. 2019;10:2889.

7. Desai DV, Kulkarni SS. Herpes simplex virus: the interplay between HSV, Host, and HIV-1. Viral Immunol. 2015;28(10):546-55.

8. Buchacz K, Patel P, Taylor M, Kerndt PR, Byers RH, Holmberg SD, et al. Syphilis increases HIV viral load and decreases CD4 cell counts in HIVinfected patients with new syphilis infections. AIDS. 2004;18(15):2075-9.

9. Duffus WA, Mermin J, Bunnell R, Byers RH, Odongo G, Ekwaru P, et al Chronic herpes simplex virus type-2 infection and HIV viral load. Int J STD AIDS. 2005;16(11):733-5.

10. Yap SH, Abdullah NK, McStea M, Takayama K, Chong ML, Crisci E, et al. HIV/Human herpesvirus co-infections: impact on tryptophan-kynurenine pathway and immune reconstitution. PLoS ONE. 2017;12(10): e0186000.

11. Schiffer JT, Swan DA, Magaret A, Schacker TW, Wald A, Corey L. Mathematical modeling predicts that increased HSV-2 shedding in HIV-1 infected persons is due to poor immunologic control in ganglia and genital mucosa. PLoS ONE. 2016;11(6): e0155124

12. Lu L, Jia M, Ma Y, Yang $L$, Chen $Z$, Ho DD, et al. The changing face of $H I V$ in China. Nature. 2008;455(7213):609-11.

13. Zhang G, Wong M, Yi P, Xu J, Li B, Ding G, et al. HIV-1 and STIs prevalence and risk factors of miners in mining districts of Yunnan, China. J Acquir Immune Defic Syndr. 2010;53(Suppl 1):S54-60.

14. Wang $H$, Wang $N$, Bi A, Wang G, Ding G, Jia M, et al. Application of cumulative odds logistic model on risk factors analysis for sexually transmitted infections among female sex workers in Kaiyuan city, Yunnan province, China. Sex Transm Infect. 2009;85(4):290-5

15. Couldwell DL, Jalocon D, Power M, Jeoffreys NJ, Chen SC, Lewis DA. Mycoplasma genitalium: high prevalence of resistance to macrolides and frequent anorectal infection in men who have sex with men in Western Sydney. Sex Transm Infect. 2018;94(6):406-10.

16. de Waaij DJ, Dubbink JH, Ouburg S, Peters RPH, Morre SA. Prevalence of Trichomonas vaginalis infection and protozoan load in South African women: a cross-sectional study. BMJ Open. 2017;7(10): e016959.

17. Nishijima T, Teruya K, Shibata S, Yanagawa Y, Kobayashi T, Mizushima D, et al. Incidence and risk factors for incident syphilis among HIV-1-infected men who have sex with men in a Large Urban HIV clinic in Tokyo, 2008-2015. PLOS ONE. 2016;11(12): e0168642.

18. Silva G, Motta H, Souza EFA, Cardoso P, Pilotto JH, Eyer-Silva WA, et al. Chlamydia trachomatis asymptomatic urethritis recurrence among males living with HIV-1. Rev Inst Med Trop Sao Paulo. 2018;60: e65.

19. Poudel KC, Poudel-Tandukar K, Palmer PH, Mizoue T, Jimba M, Kobayashi $J$, et al. Coinfection of sexually transmitted infections among HIV-positive individuals: cross-sectional results of a community-based positive living with HIV (POLH) study in Nepal. J Int Assoc Provid AIDS Care. 2017;16(4):338-46.
20. Kakaire O, Byamugisha JK, Tumwesigye NM, Gamzell-Danielsson K. Prevalence and factors associated with sexually transmitted infections among HIV positive women opting for intrauterine contraception. PLoS ONE. 2015;10(4): e0122400

21. Xian Y, Zhu B, Zhang X, Ma P, Wei Y, Xia H, et al. Risk factors associated with sexually transmitted infections among HIV infected men who have sex with men. PLoS ONE. 2017:12(2): e0170635.

22. Carcamo CP, Campos PE, Garcia PJ, Hughes JP, Garnett GP, Holmes KK, et al. Prevalences of sexually transmitted infections in young adults and female sex workers in Peru: a national population-based survey. Lancet Infect Dis. 2012;12(10):765-73.

23. Lowe S, Mudzviti T, Mandiriri A, Shamu T, Mudhokwani P, Chimbetete C, et al. Sexually transmitted infections, the silent partner in HIV-infected women in Zimbabwe. South Afr J HIV Med. 2019;20(1):849.

24. Garland SM, Steben M. Genital herpes. Best Pract Res Clin Obstet Gynaecol. 2014;28(7):1098-110.

25. Des Jarlais DC, Arasteh K, Feelemyer J, McKnight C, Tross S, Perlman DC, et al. Decline in Herpes simplex virus type 2 among non-injecting heroin and cocaine users in New York City, 2005 to 2014: prospects for avoiding a resurgence of human immunodeficiency virus. Sex Transm Dis. 2017:44(2):85-90

26. Hu QH, Xu JJ, Chu ZX, Zhang J, Yu YQ, Yu H, et al. Prevalence and determinants of Herpes simplex virus type 2 (HSV-2)/syphilis co-infection and HSV-2 mono-infection among human immunodeficiency virus positive men who have sex with men: a cross-sectional study in Northeast China. Jpn J Infect Dis. 2017;70(3):284-9.

27. Chen L, Yang J, Ma Q, Pan X. Prevalence of active syphilis infection and risk factors among HIV-positive MSM in Zhejiang, China in 2015: a crosssectional study. Int J Environ Res Public Health. 2019. https://doi.org/10. 3390/ijerph16091507.

28. Dean BB, Scott M, Hart R, Battalora L, Novak RM, Durham MD, et al. Sexually transmitted disease testing of human immunodeficiency virus-infected men who have sex with men: room for improvement. Sex Transm Dis. 2017;44(11):678-84.

29. Kularatne RS, Muller EE, Maseko DV, Kufa-Chakezha T, Lewis DA. Trends in the relative prevalence of genital ulcer disease pathogens and association with HIV infection in Johannesburg, South Africa, 2007-2015. PLoS ONE. 2018;13(4): e0194125.

30. Mungati M, Machiha A, Mugurungi $\mathrm{O}$, Tshimanga M, Kilmarx PH, Nyakura $J$, et al. The etiology of genital ulcer disease and coinfections with Chlamydia trachomatis and Neisseria gonorrhoeae in Zimbabwe: results from the Zimbabwe STI etiology study. Sex Transm Dis. 2018:45(1):61-8.

31. Jean Louis F, Galbaud G, Leonard M, Pericles E, Journel I, Buteau J, et al. Prevalence of Neisseria gonorrhoeae and Chlamydia trachomatis in men having sex with men in Port-au-Prince, Haiti: a cross-sectional study. BMJ Open. 2020;10(3): e033976.

32. Footman A, Dionne-Odom J, Aaron KJ, Raper JL, Van Der Pol B. Performance of 4 molecular assays for detection of Chlamydia and Gonorrhea in a sample of human immunodeficiency virus-positive men who have sex with men. Sex Transm Dis. 2020;47(3):158-61.

33. Daley GM, Russell DB, Tabrizi SN, McBride J. Mycoplasma genitalium: a review. Int J STD AIDS. 2014;25(7):475-87.

34. Rodrigues LLS, Hardick J, Nicol AF, Morgado MG, Martinelli KG, de Paula VS, et al. Sexually transmitted infections among HIV-infected and HIVuninfected women in the Tapajos region, Amazon, Brazil: self-collected vs. clinician-collected samples. PLoS ONE. 2019;14(4): e0215001.

35. Napierala Mavedzenge S, Muller EE, Lewis DA, Chipato T, Morrison CS, Weiss HA. Mycoplasma genitalium is associated with increased genital HIV type 1 RNA in Zimbabwean women. J Infect Dis. 2015;211(9):1388-98.

36. Roxby AC, Yuhas K, Farquhar C, Bosire R, Mbori-Ngacha D, Richardson BA, et al. Mycoplasma genitalium infection among HIV-infected pregnant African women and implications for mother-to-child transmission of HIV. AIDS. 2019;33(14):2211-7.

37. Yang $X$, Su B, Zhang $X$, Liu Y, Wu H, Zhang T. Incomplete immune reconstitution in HIV/AIDS patients on antiretroviral therapy: challenges of immunological non-responders. J Leukoc Biol. 2020;107(4):597-612.

38. Lagathu C, Bereziat V, Gorwood J, Fellahi S, Bastard JP, Vigouroux C, et al. Metabolic complications affecting adipose tissue, lipid and glucose metabolism associated with HIV antiretroviral treatment. Expert Opin Drug Saf. 2019;18(9):829-40. 
39. Waters DD, Hsue PY. Lipid abnormalities in persons living with HIV infection. Can J Cardiol. 2019;35(3):249-59.

40. Fasciana T, Capra G, Di Carlo P, Cala C, Vella M, Pistone G, et al. Sociodemographic characteristics and sexual behavioral factors of patients with sexually transmitted infections attending a hospital in Southern Italy. Int J Environ Res Public Health. 2021. https://doi.org/10.3390/ijerph1809 4722.

41. Keshinro B, Crowell TA, Nowak RG, Adebajo S, Peel S, Gaydos CA, et al. High prevalence of HIV, chlamydia and gonorrhoea among men who have sex with men and transgender women attending trusted community centres in Abuja and Lagos, Nigeria. J Int AIDS Soc. 2016;19(1):21270.

42. Caruso G, Giammanco A, Virruso R, Fasciana T. Current and future trends in the laboratory diagnosis of sexually transmitted infections. Int J Environ Res Public Health. 2021. https://doi.org/10.3390/ijerph18031038.

\section{Publisher's Note}

Springer Nature remains neutral with regard to jurisdictional claims in published maps and institutional affiliations.

- fast, convenient online submission

- thorough peer review by experienced researchers in your field

- rapid publication on acceptance

- support for research data, including large and complex data types

- gold Open Access which fosters wider collaboration and increased citations

- maximum visibility for your research: over $100 \mathrm{M}$ website views per year

At BMC, research is always in progress.

Learn more biomedcentral.com/submissions 